\title{
PREGNANT WOMEN'S KNOWLEDGE AND PERCEPTION OF EXCLUSIVE BREASTFEEDING IN SELECTED HOSPITALS IN IKORODU, LAGOS STATE, NIGERIA
}

\section{Chinenye-Julius Augusta Ezinne, Oduyoye Omobola Oyebola and Uduh Jennifer Ulonma}

${ }^{1}$ Department of Public Health, School of Public and Allied Health, Babcock University, Ilisan Remo, Ogun State, Nigeria.

Corresponding Author Email: agbanyimezinne@gmail.com

Cite this article:

Chinenye-Julius A.E., Oduyoye O.O., Uduh J.U. (2021), Pregnant Women's Knowledge and Perception of Exclusive Breastfeeding in Selected Hospitals in Ikorodu, Lagos State, Nigeria. African Journal of Health, Nursing and Midwifery 4(5), 59-74. DOI: 10.52589/AJHNMOG6UQAAZ.

\section{Manuscript History \\ Received: 5 July 2021 \\ Accepted: 4 Aug 2021 \\ Published: 17 Aug 2021}

Copyright $(9) 2020$ The Author(s). This is an Open Access article distributed under the terms of Creative Commons AttributionNonCommercial-NoDerivatives 4.0 International (CC BY-NC-ND 4.0 ), which permits anyone to share, use, reproduce and redistribute in any medium, provided the original author and source are credited.
ABSTRACT: Introduction: Exclusive breastfeeding is a public health intervention and one of the most important strategies for improving infant survival rates. Generally, breastfeeding is practiced all over the world, though with variation in duration. This study therefore examined the level of knowledge and perception of exclusive breastfeeding among pregnant women in Ikorodu, Lagos State. Methodology: In this study, a convenience sampling method was used in selecting 174 respondents from the two selected private hospitals in Ikorodu, Lagos. The instrument for this study was a questionnaire which was well-structured and data obtained from the questionnaire was coded and then inputted into the computer. Statistical Package for Social Sciences (SPSS) version 21.0 was used for this analysis. Inferential statistics such as logistic regression and Pearson's correlation test were also used to check for association. The level of significance used was 0.05. Result: The result of the study revealed that most (39.1\%) of the respondents were between the ages of 25-29 years. Majority (69.5\%) of the respondents were married and most (42\%) of the respondents had tertiary education. Respondents' level of knowledge measured on a 14point rating scale showed that the respondents scored a mean of $5.22 \pm 2.28$ which translated to a level of knowledge prevalence of $37.3 \%$. Respondents' perception measured on a 108-point rating showed that they scored a mean of $66.23 \pm 8.12$ translated to perception prevalence of $61 \%$. Conclusion: In conclusion, younger mothers practiced exclusive breastfeeding, while older mothers practiced non-exclusive breastfeeding of their babies. Mothers with a higher level of education practiced exclusive breastfeeding, while mothers with low or no educational attainment practiced non-exclusive breastfeeding of their babies.

KEYWORDS: Exclusive Breastfeeding, Knowledge, Perception, Pregnant Women and Antenatal. 


\section{INTRODUCTION}

Exclusive breastfeeding is a public health intervention and one of the most important strategies for improving infant survival rates. In 2012, World Health Organization member states endorsed and committed to support the implementation and monitoring of the "Comprehensive implementation plan on maternal, infant and young child nutrition", with one of the six targets being to increase $50 \%$ the rate of exclusive breastfeeding for the first six months by 2025 (WHO, 2012). Generally, breastfeeding is practiced all over the world, though with variation in duration.

Apart from ensuring that the infants have the best nutrition and adequate protection from infections and diseases, exclusive breastfeeding may increase the likelihood of continued breastfeeding for at least the first year of life (American Academy of Pediatrics, 2005). Eastern and southern Africa had the highest rates of exclusive breastfeeding, West and Central Africa had the lowest rates of exclusive breastfeeding with Nigeria having one of the lowest and declining rates in Africa from 28\% in 1999 to $17 \%$ in 2013 (WHO, 2012).

Exclusive Breast Feeding (EBF) is when an infant is given its entire nutrient from human breast milk and receives no complementary food during the first six months of birth. Exclusive breastfeeding for the first six months of life offers many health benefits to both the mother and child (WHO, 2012). Its benefits to the child include lower risk of infection, prevention of allergies, and it provides all the required nutrients. Weight loss, contraction of the uterus, affordability compared to infant formula, and a delayed return to fertility are some of the benefits to the mothers. It also promotes bonding for both the mother and child. Exclusively breastfed infants are much less likely to die from diarrhea, acute respiratory infections and other diseases. They are healthier, have fewer hospitalizations, and lower mortality rates than formula fed infants (Ajayi, Hellandendu \& Odekunle 2011).

Breastfeeding a baby at least once every 2-3 hours encourages constant supply of milk, and breast feeding 8 times a day tends to facilitate abundant milk supply in most women during the first 4 months or more after delivery. Many employed mothers find it difficult to meet up with the above requirement of exclusive breastfeeding if the nature of their job does not afford them the opportunity (Essien \& Samson Akpan, 2013). Breastfeeding served and continues to serve as an appropriate method through which newborns are offered essential nutrients necessary for optimal growth and intellectual development.

The prevalence of exclusive breastfeeding rates at 6 months of age was 17\% in Nigeria in 2014 . Early initiation and practice of exclusive breastfeeding has been reported to reduce neonatal mortality by up to $22 \%$ and infant mortality by $13 \%$ respectively. A national survey done in Nigeria in 2008 showed that exclusive breastfeeding rates still remain very low at $13 \%$ (Onah, Ebeneche \& Ezechukwu, 2014). The success of EBF has been attributed to several factors such as provision of accurate information, support to breastfeeding mothers and perception (beliefs and attitude) of mothers, (Wambach \& Edegbai, 2005). Under-five mortality rate in Nigeria is as high as 183 per 1000 children and infant mortality rate in the rural areas. Nigeria has been found to be exceptionally higher in areas with poor hygiene and poor sanitation, among other factors (WHO, 2012).

Nigeria is still saddled with a high incidence of malnutrition and its associated infant mortality. It is not definite or clear whether the demographic factors significantly or insignificantly 
influence the willingness of pregnant women to adopt exclusive breastfeeding. It is remarkable that up till recently, the principal attention has been demographic factors and the practice of exclusive breastfeeding. None of the studies conducted over the years is concerned much with demographic factors and the willingness to adopt exclusive breastfeeding. Therefore, the study proposed to examine demographic determinants of nursing mothers' willingness to adopt exclusive breastfeeding.

\section{METHODOLOGY}

This research is a quantitative study that employed a descriptive cross-sectional study on knowledge and perception of exclusive breastfeeding in selected hospitals in Ikorodu, Lagos State, which is located in the South-western part of the Nigerian federation. Ikorodu is a city in Lagos State, Nigeria, that is located in North-eastern Lagos State, along the Lagos lagoon. It shares a boundary with Ogun State. Ikorodu had an estimated population of 535,619 as at the 2006 census. The distance in which Ikorodu is situated is approximately $36 \mathrm{~km}$ North of Lagos. In the South, the town is bounded by the lagoon, with a common boundary with Ogun State on the North, while in the East, it has a common boundary with Agbowa-Ikosi, a town in Epe. The hospitals that were used for the study were selected private hospitals in Ikorodu, Lagos. They include Oak Hospital and Ajayi Centre Hospital. The study population were pregnant women attending antenatal clinics at the selected hospitals. The study inclusion criteria were participants attending antenatal clinics in the hospitals while the exclusion criteria were women who were within the hospital environment but not pregnant. Convenience sampling technique was used to select 174 participants. The instrument for this study was a well-structured questionnaire which contained questions that reflected the stated objective of this study. Face and content validity was carried out by the researcher's supervisor to evaluate and to standardize the instrument. A reliability test was conducted which yielded a Cronbach alpha score of 0.72 , which means that the instrument is valid statistically. The instrument was grouped into 4 categories:

Section A: Socio-demographic

Section B: Level of knowledge of pregnant women on exclusive breastfeeding

Section C: Perceptions of pregnant women towards exclusive breastfeeding

Section D: Factors that hinder/barriers of the practice on exclusive breastfeeding

Data obtained from the questionnaire was coded and then inputted into the computer. Statistical Package for Social Sciences (SPSS) version 23.0 was used for this analysis. Descriptive statistics such as frequency table, percentage, bar chart and pie chart were used to present the result while inferential statistics such as the Pearson's correlation test was also used to check for association. The level of significance used was 0.05 . Ethical clearance was obtained from Babcock University Health Research Ethics Committee. Information collected from the participants was with a high level of confidentiality so as to protect private information. The names of the respondents were not disclosed since the instrument did not require them to write their names. The identities of the participants were protected from the public and informed consent was signed by all of them. 


\section{RESULT}

\section{Socio-Demographic Data}

The demographic distribution of the respondents as presented in Table 1 below revealed that $39.1 \%$ of the respondents are between the age categories of $25-29$ years, $27 \%$ of the respondents between the age category of 20-24 years, and the least age category was $6.9 \%$ of the respondents between 15-19 years. Majority of the respondents (69.5\%) are married. Most of the respondents (42\%) have a tertiary level of education. This shows that a vast majority of the respondents are well educated. The religious distribution of the respondents showed that $81.0 \%$ of the respondents are Christians while $16.7 \%$ of the respondents practice Islamic religion. Also, it can be seen that $31.0 \%$ of the respondents are traders while those that are housewives and civil servants constitute $34.5 \%$ and $34.5 \%$ respectively. In the same vein, the classification of the respondents according to their monthly income revealed that $77.0 \%$ of the respondents earn above N10,000 with $20.7 \%$ of the respondents not earning any monthly income.

Table 1: Demographic Distribution of Respondents

\section{Demographic variables for \\ Consideration}

Age (in years)

15-19

20-24

25-29

30-34

35-above

Marital status

Single

Married

Divorced

Educational level

None

Primary

Secondary

Tertiary

Religion

Christianity

Islam

Traditional worshipper

Others

Occupation

Housewife

Traders

Civil servants

Monthly income

No salary

Below \#5000

\section{Respondents in this study $=174$} Frequency (n)

Percentage $(\%)$

12

6.9

47

27.0

68

39.1

28

16.1

19

10.9

\section{2}

29.9

121

69.5

1

0.6

4.0

15.5

38.5

42.0

73

81.0

141

16.7

29

1.7

0.6

60

34.5

$54 \quad 31.0$

$60 \quad 34.5$

$36 \quad 20.7$

$4-2.3$ 
\#5000-\#10,000

$\# 10,000-\# 20,000$

\#20,000-\#30,000

44

14

\#30,000-above
24.7

25.3

8.0

19.0

\section{Respondents' Level of Knowledge of Pregnant Women on Exclusive Breastfeeding}

Table 2 below presents the analysis on the level of knowledge of pregnant women on exclusive breastfeeding. It was shown that $75.9 \%$ of the respondents have heard of exclusive breastfeeding with $24.7 \%$ of the respondents having first heard of the information on exclusive breastfeeding from their family and friends while $44.8 \%$ first heard of it from the hospital, $21.3 \%$ from the television, $11.2 \%$ from the internet/social media, and $19.0 \%$ from newspapers. The analysis also revealed that $71.8 \%$ of the respondents believed that exclusive breastfeeding means feeding the baby with breast milk only. $55.7 \%$ of the respondents believed that a baby should be breastfed on demand. It was also shown in the analysis that $43.1 \%$ of the respondents believed that discarding the first milk or colostrum is the best practice to do. Majority $(75.9 \%)$ of the respondents believed that breast milk alone is enough for an infant during their first 6 months of life. More than half $(60.3 \%)$ of the respondents believed that breastfeeding is cost effective. Also, $65.5 \%$ of the respondents agreed to practice exclusive breastfeeding.

Table 2: Respondents' Level of Knowledge on Exclusive Breastfeeding

\section{Variable}

Have you heard of exclusive breastfeeding?

Yes

No

Exclusive breastfeeding means?

Feeding the baby with breastmilk and water only

Yes

No

Feeding the baby with breastmilk only

Yes

No

Feeding the baby with breastmilk, pap and water

Yes

No

Feeding the baby with breastmilk, formula and water

Yes

No

Feeding the baby with breastmilk, water and indomie

Yes

No

\section{Respondents in the study $=174$}

Frequency (n) Percentage $(\%)$

132

42

44

130

125

49

30

144

20

154

11

163
75.9

71.8

28.2

17.2

82.8

11.5

88.5

6.3

93.7 
A baby should be breastfed? Three to four times

Yes

No

Morning, afternoon and night

Yes

No

On demand

Yes

No

Only when crying

Yes

No

At night

Yes

No

Discarding of the first milk or colostrum is the best practice?

Yes

No

months of life?

Breast milk alone is enough for an infant during the first 6 mont
Yes

No

Exclusive breastfeeding is cost effective?

Yes

No

Are you going to practice exclusive breastfeeding?

Yes

\section{Perceptions of Pregnant Women towards Exclusive Breastfeeding}

\section{Perceived Severity}

The respondents' perception of the severity as presented in Table 3.1 below showed that $58.6 \%$ of the respondents believed that engaging in exclusive breastfeeding could lead to a soreness of breast. Also, $48.3 \%$ of the respondents believed that not practicing exclusive breastfeeding could lead to malnutrition for the infant. $31 \%$ of the respondents did not believe that not practicing exclusive breastfeeding could lead to poor mental health of the infant. Also, 30.5\% of the respondents believed that exclusive breastfeeding is essential for the infant to avoid obesity, while $34.5 \%$ believed otherwise. It was observed that $21.8 \%$ of the respondents believed that engaging in exclusive breastfeeding makes the babies weak while $43.1 \%$ believed otherwise; $32.8 \%$ of the respondents believed that not practicing exclusive breastfeeding makes their babies prone to infections and diseases while $15.5 \%$ believed otherwise. 
Table 3.1: Respondent's Perception on the Severity to Practice Exclusive Breastfeeding

\begin{tabular}{|c|c|c|c|c|c|}
\hline Statement & $\begin{array}{l}\text { Strongly } \\
\text { agree } \\
\text { F (\%) }\end{array}$ & $\begin{array}{l}\text { Agree } \\
\text { F }(\%)\end{array}$ & $\begin{array}{l}\text { Disagr } \\
\text { F }(\%)\end{array}$ & & $\begin{array}{l}\text { Strongly } \\
\text { Disagree } \\
\text { F (\%) }\end{array}$ \\
\hline $\begin{array}{l}\text { Engaging in exclusive breastfeeding could } \\
\text { lead to soreness of the breast }\end{array}$ & $40(23.0)$ & $102(58.6)$ & $15(8.6)$ & \multicolumn{2}{|c|}{$17(9.8)$} \\
\hline $\begin{array}{l}\text { Not practicing exclusive breastfeeding } \\
\text { Could lead to malnutrition for the infant }\end{array}$ & $30(17.2)$ & $84(48.3)$ & $17(9.8)$ & \multicolumn{2}{|c|}{$43(24.7)$} \\
\hline $\begin{array}{l}\text { Not practicing exclusive breastfeeding } \\
\text { could lead to poor mental health of the infant }\end{array}$ & $\begin{array}{l}47(27.0) \\
t\end{array}$ & $54(31.0)$ & 19(10.9) & \multicolumn{2}{|c|}{$54(31.0)$} \\
\hline $\begin{array}{l}\text { Exclusive breastfeeding is essential for } \\
\text { an infant to avoid obesity }\end{array}$ & $44(25.3)$ & $53(30.5)$ & $17(9.8)$ & \multicolumn{2}{|c|}{$60(34.5)$} \\
\hline $\begin{array}{l}\text { Engaging in exclusive breastfeeding makes } \\
\text { the baby weak }\end{array}$ & $38(21.8)$ & $30(17.2)$ & 31(17.8) & \multicolumn{2}{|c|}{$75(43.1)$} \\
\hline $\begin{array}{l}\text { Not practicing exclusive breastfeeding makes } \\
\text { the baby prone to infections and diseases }\end{array}$ & s $56(32.3)$ & $57(32.8)$ & $27(15.5)$ & \multicolumn{2}{|c|}{$34(19.5)$} \\
\hline
\end{tabular}

\section{Perceived Susceptibility}

The respondents' perception of the susceptibility as presented in Table 3.2 below showed that a total of $39.1 \%$ believed that they are at risk of depression if they practice exclusive breastfeeding while $28.7 \%$ of the respondents believed otherwise. Also, less than half $(39.7 \%)$ of the respondents believed that their babies are at risk of infections if he/she takes colostrum of the breast. Also, $21.3 \%$ of the respondents believed that they are at risk of losing their figures if they practice exclusive breastfeeding while $40.2 \%$ believed otherwise. Less than half of the respondents $(25.3 \%)$ believed that their babies tend to have a slower/stunted growth if they practice exclusive breastfeeding while $39.7 \%$ believed otherwise.

Table 3.2: Respondents' Perception on Susceptibility to Practicing Exclusive Breastfeeding

\begin{tabular}{llccc}
\hline Statement & $\begin{array}{l}\text { Strongly } \\
\text { agree } \\
\text { F (\%) }\end{array}$ & $\begin{array}{l}\text { Agree } \\
\text { F (\%) }\end{array}$ & $\begin{array}{l}\text { Disagree } \\
\text { F (\%) }\end{array}$ & $\begin{array}{l}\text { Strongly } \\
\text { Disagree } \\
\text { F (\%) }\end{array}$ \\
\hline $\begin{array}{l}\text { I am at risk of depression if I practice } \\
\text { exclusive breastfeeding }\end{array}$ & $29(16.7)$ & $68(39.1)$ & $27(15.5)$ & $50(28.7)$ \\
$\begin{array}{l}\text { My baby is at risk of infections if he/she } \\
\text { takes the colostrum of the breast }\end{array}$ & $24(13.8)$ & $69(39.7)$ & $24(13.8)$ & $57(32.8)$ \\
$\begin{array}{l}\text { I am at risk of losing my figure if I practice } \\
\text { exclusive breastfeeding }\end{array}$ & $31(17.8)$ & $37(21.3)$ & $36(20.7)$ & $70(40.2)$ \\
$\begin{array}{l}\text { My baby tends to have a slower/stunted } \\
\text { growth if I practice exclusive breastfeeding }\end{array}$ & $44(25.3)$ & $36(20.7)$ & $25(14.4)$ & $69(39.7)$
\end{tabular}




\section{Perceived Benefits}

The perception of the respondents on the benefits of breastfeeding as presented in Table 3.3 below showed that the majority $(60.3 \%)$ of the respondents believed that their babies will be healthy if they practice exclusive breastfeeding. Also, $46.6 \%$ of the respondents believed that exclusive breastfeeding creates bonds between mother and child. It can also be seen that $33.9 \%$ of the respondents believed that breastfeeding is a natural way of family planning. In the same vein, a total of $35.1 \%$ of the respondents believed that they will be fit and healthy mothers if they practice exclusive breastfeeding. More than half (54.6\%) of the respondents believed that their babies would not be exposed to certain infections if they practice exclusive breastfeeding. However, a total of $34.5 \%$ of the respondents believed that babies less than 6 months old cannot survive without water while $32.8 \%$ believed otherwise.

Table 3.3: Respondents' Perception on the Benefits of Practicing Exclusive Breastfeeding

\begin{tabular}{lcccc}
\hline Statement & $\begin{array}{l}\text { Strongly } \\
\text { agree } \\
\text { F (\%) }\end{array}$ & $\begin{array}{l}\text { Agree } \\
\text { F (\%) }\end{array}$ & $\begin{array}{l}\text { Disagree } \\
\text { F (\%) }\end{array}$ & $\begin{array}{l}\text { Strongly } \\
\text { Disagree } \\
\text { F (\%) }\end{array}$ \\
\hline $\begin{array}{l}\text { My baby will be healthy if I practice } \\
\text { exclusive breastfeeding }\end{array}$ & $53(30.5)$ & $105(60.3)$ & $2(1.1)$ & $14(8.0)$ \\
$\begin{array}{l}\text { Exclusive breastfeeding creates bonds } \\
\text { between mother and child }\end{array}$ & $73(42.0)$ & $81(46.6)$ & $4(2.3)$ & $16(9.2)$ \\
$\begin{array}{l}\text { Breastfeeding is a natural way of family } \\
\text { planning }\end{array}$ & $59(33.9)$ & $44(25.3)$ & $13(7.5)$ & $58(33.3)$ \\
$\begin{array}{l}\text { I will be a fit and healthy mother if I } \\
\text { practice exclusive breastfeeding }\end{array}$ & $58(33.3)$ & $61(35.1)$ & $10(5.7)$ & $45(25.9)$ \\
$\begin{array}{l}\text { Exclusive breastfeeding brings the uterus } \\
\text { back to shape }\end{array}$ & $39(22.4)$ & $109(62.6)$ & $15(8.6)$ & $11(6.3)$ \\
$\begin{array}{l}\text { My baby wouldn't be exposed to certain } \\
\text { infections if I practice exclusive breastfeeding }\end{array}$ & $62(35.6)$ & $95(54.6)$ & $5(2.9)$ & $12(6.9)$ \\
$\begin{array}{l}\text { Babies less than 6 months cannot survive } \\
\text { without water }\end{array}$ & $60(34.5)$ & $30(17.2)$ & $27(15.5)$ & $57(32.8)$ \\
& & & &
\end{tabular}

\section{Perceived Barriers}

The analysis from Table 3.4 below showing the respondents' perception of the barriers working against the practice of exclusive breastfeeding revealed that $48.9 \%$ of the respondents claimed that they do not breastfeed their babies because of external pressure from people around them. Also, $36.8 \%$ of the respondents believed that their babies cannot suck because they have deformed lips. Also, only $20.1 \%$ of the respondents claimed their babies refuse to take breast milk. $16.1 \%$ of the respondents believed that their babies cannot breastfeed well because of the size of their nipples. $24.7 \%$ of the respondents believed that practicing exclusive breastfeeding is time consuming. Less than half of the respondents (31.6\%) believed that they have support whenever they are breastfeeding their babies. A total of $37.4 \%$ also believed that their health condition may affect the baby's feeding. However, a total of $29.9 \%$ of the respondents did not 
believe that it is shameful to breastfeed their babies in public. Similarly, $22.4 \%$ of the respondents claimed that their husbands do not allow them to breastfeed their baby exclusively. Also, less than half of the respondents $(32.2 \%)$ believed that the state or environment of their work doesn't allow them to exclusively breastfeed their baby.

Table 3.4 Respondents' Perception of the Barriers to the Practice of Exclusive Breastfeeding

\begin{tabular}{|c|c|c|c|c|}
\hline Statement & $\begin{array}{l}\text { Strongly } \\
\text { agree } \\
\text { F (\%) }\end{array}$ & $\begin{array}{l}\text { Agree } \\
\text { F (\%) }\end{array}$ & $\begin{array}{l}\text { Disagree } \\
\text { F }(\%)\end{array}$ & $\begin{array}{l}\text { Strongly } \\
\text { Disagree } \\
\text { F (\%) }\end{array}$ \\
\hline $\begin{array}{l}\text { I do not breastfeed my baby because of } \\
\text { external pressure from people around me }\end{array}$ & $27(15.5)$ & $85(48.9)$ & $30(17.2)$ & $32(18.4)$ \\
\hline $\begin{array}{l}\text { I have a baby with deformed lips; the baby } \\
\text { cannot suck }\end{array}$ & $31(17.8)$ & $64(36.8)$ & $35(20.1)$ & $44(25.3)$ \\
\hline My baby refuses to take breast milk & $35((20.1)$ & $33(19.0)$ & $30(17.2)$ & $76(43.7)$ \\
\hline $\begin{array}{l}\text { With the size of my nipples, the baby cannot } \\
\text { breastfeed well }\end{array}$ & $40(23.0)$ & $28(16.1)$ & $30(17.2)$ & $76(43.7)$ \\
\hline $\begin{array}{l}\text { Practicing exclusive breastfeeding is time } \\
\text { consuming }\end{array}$ & $38(21.8)$ & $43(24.7)$ & $28(16.1)$ & $65(37.4)$ \\
\hline $\begin{array}{l}\text { I have support whenever I am breastfeeding } \\
\text { my baby }\end{array}$ & $49(28.2)$ & $55(31.6)$ & $18(10.3)$ & $52(29.9)$ \\
\hline $\begin{array}{l}\text { My health condition may affect the baby's } \\
\text { feeding }\end{array}$ & $38(21.8)$ & $65(37.4)$ & $25(14.4)$ & $46(26.4)$ \\
\hline $\begin{array}{l}\text { It is shameful to breastfeed my baby in } \\
\text { public }\end{array}$ & $32(18.4)$ & $64(36.8)$ & $26(14.9)$ & $52(29.9)$ \\
\hline $\begin{array}{l}\text { My husband doesn't allow me to exclusively } \\
\text { breastfeed my baby }\end{array}$ & $34(19.5)$ & $39(22.4)$ & $28(6.1)$ & $73(42.0)$ \\
\hline $\begin{array}{l}\text { The state or environment of my work doesn't } \\
\text { allow me to exclusively breastfeed my baby }\end{array}$ & $42(24.1)$ & $56(32.2)$ & $24(13.8)$ & $52(29.9)$ \\
\hline
\end{tabular}

\section{Analysis of Knowledge and Perception Level of Pregnant Women to the Practice of Exclusive Breastfeeding}

Following the work of Ashur (1977), measurement scale, proportion of scores greater than 70\% is considered as high and adequate level with respect to the variable being measured. From table 4 shown below, the pregnant women's level of knowledge and perception on exclusive breastfeeding suggests that the respondents' level of knowledge is low $(35.7 \%)$ with a mean of 5.224 and a maximum scale of 14 . Also, the respondents' perception level is low $(61.1 \%)$, with a mean of 66.236 and a maximum scale of 108 . 
Table 4: Analysis of Knowledge and Perception Level of Pregnant Women to the Practice of Exclusive Breastfeeding

\begin{tabular}{lcccc}
\hline & $\begin{array}{l}\text { Max point on } \\
\text { scale of } \\
\text { measure }\end{array}$ & Mean & Std. Deviation & \% \\
\hline $\begin{array}{l}\text { Knowledge of } \\
\text { pregnant women }\end{array}$ & 14 & 5.224 & 2.284 & 37.3 \\
$\begin{array}{l}\text { Perception of } \\
\text { pregnant women }\end{array}$ & 108 & 66.236 & 8.126 & 61.1 \\
\hline
\end{tabular}

\section{Test of Hypothesis}

Two hypotheses were tested for this study. In testing these hypotheses, Pearson Correlation was conducted at 0.05 level of significance. The decision rule applied was that if the p-value computed was less or equal to the cut-off $\mathrm{p}$-value of 0.05 , the null hypothesis would be rejected in favour of the alternative hypothesis and vice-versa.

\section{Hypothesis One:}

$\mathrm{H}_{0}$ : There is no significant relationship between the socio-demographic characteristics and the level of knowledge on exclusive breastfeeding.

$\mathrm{H}_{\mathrm{i}}$ : There is a significant relationship between the socio-demographic characteristics and level of knowledge on exclusive breastfeeding.

As shown in Table 5 below, it revealed the regression coefficient result, showing $\mathrm{R}^{2}=0.380$; the variation in the dependent variable is caused by variations in the independent variable. The result is significantly less than $5 \%$ which indicates that the model is relatively of good fit.

The coefficient of the respondents' socio-demographic characteristics, marital status with pvalue 0.000 less than 0.05 , educational level with p-value 0.001 less than 0.05 , and monthly income with p-value 0.055 less than 0.05 are factors that significantly influence knowledge level on exclusive breastfeeding. In conclusion, the null hypothesis will be rejected and an alternative hypothesis will be accepted, stating that respondents' socio-demographic characteristics significantly influenced their knowledge on exclusive breastfeeding. 
Table 5: Level of Knowledge and Socio-Demographic Determinants of Pregnant Women on Exclusive breastfeeding

\begin{tabular}{|l|r|r|r|r|r|}
\hline \multirow{2}{*}{ Model } & \multicolumn{2}{|c|}{$\begin{array}{c}\text { Unstandardized } \\
\text { Coefficients }\end{array}$} & $\begin{array}{c}\text { Standardized } \\
\text { Coefficients }\end{array}$ & \multicolumn{1}{c|}{$\mathrm{T}$} & \multicolumn{1}{c|}{ Sig. } \\
\cline { 2 - 6 } & \multicolumn{1}{|c|}{$\mathrm{B}$} & Std. Error & \multicolumn{1}{c|}{ Beta } & & \\
\hline (Constant) & 3.849 & .979 & & 3.932 & .000 \\
Age & -.035 & .033 & -.081 & -1.044 & .298 \\
Marital status & 1.606 & .380 & .330 & 4.227 & .000 \\
Educational level & .124 & .035 & .270 & 3.503 & .001 \\
Occupation & -.342 & .391 & -.071 & -.875 & .383 \\
Monthly income & $3.294 \mathrm{E}-5$ & .000 & .160 & 1.933 & .055 \\
& & & & & \\
\hline
\end{tabular}

a. Dependent variable: Knowledge on EBF

\section{Hypothesis Two}

$\mathrm{H}_{0}$ : There is no significant relationship between the socio-demographic characteristics and the perception of exclusive breastfeeding.

$\mathrm{H}_{\mathrm{i}}$ : There is a significant relationship between the socio-demographic characteristics and the perception of exclusive breastfeeding.

As shown in the table 6 below, the regression coefficient result, showing $\mathrm{R}^{2}=0.448(44.8 \%)$, the variation in the dependent variable is caused by variations in the independent variable. The result is significantly less than 5\%; this indicates that the model is relatively of good fit.

The coefficient of the respondents' socio-demographic characteristics, educational level with p-value 0.050 less than 0.05 , occupation with p-value 0.002 less than 0.05 , and monthly income with p-value 0.000 less than 0.05 are factors that significantly influence the perception of exclusive breastfeeding. In conclusion, the null hypothesis will be rejected and an alternative hypothesis will be accepted, stating that respondents' socio-demographic characteristics significantly influenced their perception of exclusive breastfeeding. 
Table 6: Perception and Socio-Demographic Characteristics of Pregnant Women on Exclusive Breastfeeding

\begin{tabular}{|l|r|r|r|r|r|}
\hline \multirow{2}{*}{ Model } & \multicolumn{2}{|c|}{$\begin{array}{c}\text { Unstandardized } \\
\text { Coefficients }\end{array}$} & $\begin{array}{l}\text { Standardized } \\
\text { Coefficients }\end{array}$ & \multicolumn{1}{c|}{$\mathrm{T}$} & \multicolumn{1}{c|}{ Sig. } \\
\cline { 2 - 6 } & \multicolumn{1}{|c|}{$\mathrm{B}$} & Std. Error & \multicolumn{1}{c|}{ Beta } & & \\
\hline (Constant) & 76.217 & 3.367 & & 22.636 & .000 \\
Age & -.197 & .114 & -.129 & -1.722 & .087 \\
Marital status & 1.465 & 1.307 & .085 & 1.121 & .264 \\
Educational level & .238 & .122 & -.145 & 1.954 & .052 \\
Occupation & 4.254 & 1.344 & .249 & 3.165 & .002 \\
Monthly income & .000 & .000 & -.402 & 5.042 & .000 \\
\hline
\end{tabular}

b. Dependent Variable: Perception on EBF

\section{Relationship between Respondents' Knowledge Level, Perception and Respondents' Willingness to Practice Exclusive Breastfeeding}

There is a negative relationship between perception and respondents' willingness to practice exclusive breastfeeding $(\mathrm{r}=-0.225, \mathrm{p}=0.003)$.

There is a positive relationship between knowledge and respondents' willingness to practice exclusive breastfeeding $(\mathrm{r}=0.300, \mathrm{p}=0.000)$.

Table 7: Relationship between Respondents' Knowledge Level, Perception and Respondents' Willingness to Practice Exclusive Breastfeeding

\section{Correlations}

\begin{tabular}{|ll|r|r|r|}
\hline & $\begin{array}{c}\text { Are you going to } \\
\text { practice } \\
\text { exclusive } \\
\text { breastfeeding? }\end{array}$ & Perception & \multicolumn{2}{|c|}{$\begin{array}{c}\text { Knowledge } \\
\text { Level }\end{array}$} \\
\hline Are you going to & Pearson Correlation & 1 & $-.225^{* *}$ & $.300^{* *}$ \\
practice exclusive & Sig. (2-tailed) & .003 & .000 \\
breastfeeding? & $\mathrm{N}$ & 174 & 174 & 174 \\
\hline Perception & Pearson Correlation & $-.225^{* *}$ & 1 & .044 \\
& Sig. (2-tailed) & .003 & 174 & .563 \\
& $\mathrm{~N}$ & $.300^{* *}$ & .044 & 174 \\
\hline Knowledge Level & Pearson Correlation & .000 & .563 & 1 \\
& Sig. (2-tailed) & 174 & 174 & 174 \\
& $\mathrm{~N}$ & & \\
\hline
\end{tabular}

**. Correlation is significant at the 0.01 level (2-tailed). 


\section{DISCUSSION}

\section{Discussion on the Socio-Demographic Characteristics of Respondents}

Findings from the study show that the majority of the respondents fell within the age group of 25-29 years. A study done by Girish and Acharya (2013) in Kerala among antenatal women also showed similar results, with $69.4 \%$ of participants belonging to the $18-30$ years age group.

Majority of the respondents knew about the importance of feeding the baby on demand. A similar study had 54\% antenatal women that knew about demand feeding (Girish et al., 2013). Less than half of the respondents had a tertiary educational level which is similar to a study finding that improved maternal educational level enhances mothers' understanding and appreciation of the demands and benefits of exclusive breastfeeding (Iliyasu et al., 2005).

\section{Discussion on the Level of Knowledge of Pregnant Women towards Exclusive Breastfeeding in Ikorodu, Lagos State}

Majority of the respondents have heard about exclusive breastfeeding which is in conformity to a study on knowledge regarding exclusive breastfeeding which revealed that the majority of the women had good knowledge about exclusive breastfeeding (Agu \& Agu, 2011). A contrary study was carried out in Kware town of Sokoto State in Nigeria where only $31 \%$ of the mothers had adequate knowledge on exclusive breastfeeding (Mogre et al., 2016).

An average percentage of the respondents knew about the importance of feeding the baby on demand. A similar study had an average percent of antenatal women that knew about feeding the baby on demand (Girish et al., 2013). Also in a contrary study, De et al. (2016) reported a higher percentage of women knowing about feeding a baby on demand.

Also, the majority of the respondents believed that breast milk alone is enough for an infant during the first 6 months of life. A contrary study among mothers in Dhaka reported a low percentage of respondents who breastfeed their baby for the first 6 months of life.

\section{Discussion on the Perception of Pregnant Women towards Exclusive Breastfeeding in Ikorodu, Lagos State}

Findings from this study showed that the majority of the respondents agreed that not practicing exclusive breastfeeding could make the baby prone to infections and diseases. Several studies indicated that breast milk promotes sensory and cognitive development, and protects the infant against infectious and chronic diseases (Kramer, 2008). In this study, majority of the respondents had a greater perception of the benefits of exclusive breastfeeding. $69.1 \%$ and $67 \%$ of women having good perception of the benefits of exclusive breastfeeding respectively in their studies were reported, and another study reported a much lower percentage of their perception of the benefits of EBF (Behera et al., 2016).

Findings from this research showed that the majority of the respondents believed that practicing exclusive breastfeeding brings the uterus back to shape. A review in 2016 found that breastfeeding exclusively would increase the chances of the mothers' uterus returning to shape, (Victoria et al., 2016). 


\section{Discussion on the Factors that Hinder the Practice of Exclusive Breastfeeding in Ikorodu, Lagos State}

Respondents' occupation also significantly influenced the practice of exclusive breastfeeding of babies, indicating high practice of exclusive breastfeeding among non-workingclass mothers. A study in Singapore revealed that although work status had no effect on the initiation of breastfeeding, it did have an effect on the duration of breastfeeding, (Ong et al., 2005). A more recent study in Northwest Ethiopia demonstrated similar findings (Chekol et al., 2017).

In this study, socio-demographic characteristics, educational level, occupation and monthly income are factors that influence the knowledge and practice of exclusive breastfeeding, which conforms to a national study in rural Ghana, where education, occupation, economic factors and marital status were the factors affecting exclusive breastfeeding (Polit et al., 2015); this also tends to conform to the findings of Textor et al. (2013) where it was observed that the socio-demographic characteristics of pregnant women determine the level of exclusive breastfeeding of their kids.

\section{CONCLUSION}

In conclusion, younger mothers practiced exclusive breastfeeding, while older mothers practiced non-exclusive breastfeeding of their babies. Mothers with a higher level of education practiced exclusive breastfeeding, while mothers with low or no educational attainment practiced non-exclusive breastfeeding of their babies. Mothers who are unemployed practiced exclusive breastfeeding, while working class mothers practiced non-exclusive breastfeeding of their babies. In essence, it is safe to conclude that the socio-demographic determinants, educational level, occupation and monthly income of the pregnant women determine their willingness to practice exclusive breastfeeding.

\section{RECOMMENDATIONS}

On the basis of the conclusions drawn, the following recommendations are made:

1) Employers of labor should extend maternity leave for nursing mothers to 6 months to enable them practice exclusive breastfeeding or establish day care centers within the working environment to enable mothers' breastfeed their babies more conveniently and adequately.

2) Special interventions should be made for older mothers with poor breastfeeding practices by healthcare workers to encourage them to endure the task of breastfeeding, through health education and nursing support to enable them to breastfeed exclusively.

3) Since health education remains the most viable means of reaching mothers on the benefits derived from exclusive breastfeeding, healthcare workers should intensify health education to provide mothers with complete and current information on the methods of exclusive breastfeeding, to increase their knowledge of benefits derived from exclusive breastfeeding of babies. 


\section{REFERENCES}

Agu U, Agu MC: Knowledge and practice of exclusive breastfeeding among mothers in a rural population in south eastern Nigeria. Trop J Med Res 2011, 15(2):39-44.

Ajayi, A. D., Hellandensis, J, \& Odekule, F. (2011) Socio-demographic correlates of breast feeding practices among mothers in Kogi State, Nigeria. West African Journal of Nursing. 22(1), 28-35.

American Academy of Pediatrics. (2005). Breastfeeding and the use of human milk. Pediatrics, 115, 496-506. doi:10.1542/ peds.2004-2491.

Behera D, Pillai AK. Intention toward optimal breastfeeding among expecting mothers in angul district of Odisha, India. Indian J Public Health. 2016;60:81-5. [PubMed] [Google Scholar

Chekol, DA, Biks, GA, Gelaw, YA, et al. (2017) Exclusive breastfeeding and mothers' employment status in Gondar town, Northwest Ethiopia: A comparative cross sectional study. International Breastfeeding Journal 12: 1-9. Google Scholar | Crossref | Medline

De M, Taraphdar P, Paul S. Awareness of breast feeding among mothers attending antenatal OPD of NRS medical college. IOSR J of Dent and Med Sci 2016;15:3-8. [Doi: 10.9790/0853-152120308].

Essien, N. C., and Samson-Akpan, P.E. (2013) Factors Influencing the practice of exclusive breastfeeding among women in Ikot Omin, Calabar, Nigeria. Mary Slessor Journal of Medicine. 12(1) 51-63

Girish HO, Acharya A, Kumar A, Venugopalan PP, Sarada Prabhakaran R K. (2013) Knowledge and practices of breastfeeding among ante-natal mothers at a teaching hospital at Kannur, Kerala: A cross-sectional study. Jour of Evolution of Med and Dent Sci 2:8996-9001.

Iliyasu Z, Kabir M, Abubakar IS, Galadanci NA. Current knowledge and practice of exclusive breastfeeding among mothers in Gwale local government area of Kano state. Nigerian Medical Practitioner. 2005;48(2):50-5. https://doi.org/10. 4314/nmp.v48i2.28764.

Kramer, M.S., and Chalmers, B. Hodnett E.D, (2016) Promotion of Breastfeeding Intervention Traial (PROBIT): A Randomized Trial in Republic of Belarus TAMA.205: 413- 420.

Mogre V, Dery M, Gaa PK. Knowledge, attitudes and determinants of exclusive breastfeeding practice among Ghanaian rural lactating mothers. Int Breastfeed J. 2016;11(1). https://doi.org/10.1186/s13006-016-0071-z.

Onah, S., Osuorah, D.I.C., Ebeneche, J., Ezechuckwu, C., Ekwochi, U., \& Ndukwu, I. (2014). Infant breastfeeding practices and maternal socio-demographic factors that influence practice of exclusive breastfeeding among mothers in Nnewi South -East Nigeria. International breastfeeding Journal 9(6).

Ong G, Yap M, Li FL, Choo TB. Impact of working status on breastfeeding in Singapore: evidence from the National Breastfeeding Survey 2001. Eur J Pub Health. 2005;15(4):424-30.

Polit, D. F., \& Hungler, B. F. (2015). Nursing research: Principles and methods. Philadelphia: J. B. Lippincott.

Textor, L., Tiedje, K., \& Yawn, B. (2013). Mexican and Somali immigrant breastfeeding initiation and counseling: A qualitative study of practices. Minnesota Medicine, 96(12), 46-50. 
Victoria C.G, Bahl R, Barros AJ, Franca GV, Horton S, Krasevec J, Murch S, Sankar M.J, Walker N, Rollins NC (2016). "Breastfeding in the $21^{\text {st }}$ century; epidemiology, mechanisms, and lifelong effect" Lancet. 387 (10017): 475-90.

Wambach, K., Campell, S.H., Gill, S. L., Datgston, J. E., Abiona, T.C \& Heing, M. J, (2005) Clinical Lactation practices: 20 years of evidence. Journal of Human Lactation, 21(3): 245-258.

World Health Organization (WHO) (2012) World Breastfeeding Week-2012-Pledge Now: 20 Years World Breastfeeding Week Partnership for Maternal, Newborn \& Child Health. http://www.who.int/pmnch/media/news/2012/2012_world_breastfeeding_week/en/ index 1.html 